\title{
Can a data driven obesity classification system identify those at risk of severe COVID-19 in the UK Biobank cohort study?
}

\begin{abstract}
Stephen Clark $\mathbb{D}^{1 凶}$, Michelle Morris $\mathbb{D}^{2}$, Nik Lomax ${ }^{3}$ and Mark Birkin ${ }^{4}$
(c) The Author(s) 2021

COVID-19 is a disease that has been shown to have outcomes that vary by certain socio-demographic and socio-economic groups. It is increasingly important that an understanding of these outcomes should be derived not from the consideration of one aspect, but by a more multi-faceted understanding of the individual. In this study use is made of a recent obesity driven classification of participants in the United Kingdom Biobank (UKB) to identify trends in COVID-19 outcomes. This classification is informed by a recently created obesity systems map, and the COVID-19 outcomes are: undertaking a test, a positive test, hospitalisation and mortality. It is demonstrated that the classification is able to identify meaningful differentials in these outcomes. This more holistic approach is recommended for identification and prioritisation of COVID-19 risk and possible long-COVID determination.
\end{abstract}

International Journal of Obesity (2021) 45:2281-2285; https://doi.org/10.1038/s41366-021-00891-6

\section{INTRODUCTION}

The COVID-19 pandemic has impacted lives globally. As healthcare professionals and scientists learn more about the disease, it becomes clearer that certain groups of people suffer more serious consequences of COVID-19. People who are overweight or living with obesity fare particularly badly. Above average prevalence of overweight and obesity is observed in patients requiring intensive care treatment [1-3]. Furthermore, the severe consequences of COVID-19 are impacting most upon adults over the age of 50, those from ethnic minority groups and the less affluent in society [3].

Drivers of obesity are complex and multifaceted [4], making the prevention and treatment for obesity challenging for all involved, from global organisations, through to the individual. It also makes relationships between COVID-19 and obesity extremely difficult to unpack. For example: are the severe consequences due solely to the weight status of an individual? Or is it weight status in combination with related comorbidities $[5,6]$ ? Alternatively, are all of these driven by deprivation, [7], where higher incidence of severe COVID-19 symptoms are observed [3].

The United Kingdom Biobank (UKB) [8] has made COVID-19 relevant data available to researchers actively working with UKB data [9]. These include information on test results, primary care data, hospital admission data and mortality for UKB participants. The timeliness of these data has allowed a body of research to be established, particularly around the role of obesity [10-12] but also ethnicity [13] and other factors such as comorbidities and vitamin deficiencies $[14,15]$.

We have developed an obesity classification system [16], with variable selection informed by the Foresight Obesity System map covering the themes of: food production, food consumption, societal influences, individual psychology, individual activity, activity environment and Biology [4], using the UKB cohort. This classification utilises 52 UKB variables composited into 23 classification variables and the k-means unsupervised classification algorithm is used to identify the classes. Pen-portraits based on how each of these classes measure against the classification variables are used to typify these seven classes as: Active workers; Retirees with healthy lifestyles; Stressed and not in work; Deprived with less-healthy lifestyles; Comfortable professionals and Comfortable families. Each class was seen to be differentiated by aspects such as gender (more males in the Stressed and not in work class), ethnicity (Retirees with healthy lifestyles were predominately white ethnicity), self-reported health (Deprived with less-healthy lifestyles had poorer health), and Education (Active workers with lower education levels).

The aim of this short communication is to investigate whether there is a relationship between our obesity classification and (a) being tested for COVID-19, (b) testing positive for COVID-19, (c) suffering acute symptoms of COVID-19 resulting in hospital admissions, or (d) suffering severe symptoms of COVID-19 resulting in death.

\section{METHODS}

We used UKB COVID-19 data up until 30 November 2020. UKB participants can be tested multiple times, and any participant with one or more positive tests is regarded as having tested positive. For hospitalisation, the ICD-10 codes of U07.1 (tested positive for

\footnotetext{
${ }^{1}$ Consumer Data Research Centre and School of Geography, University of Leeds, LEEDS LS2 9JT, UK. ${ }^{2}$ School of Medicine and Consumer Data Research Centre, University of Leeds, LEEDS LS2 9JT, UK. ${ }^{3}$ School of Geography and Consumer Data Research Centre, University of Leeds, LEEDS LS2 9JT, UK. ${ }^{4}$ Consumer Data Research Centre and School of Geography, University of Leeds, LEEDS LS2 9JT, UK. ${ }^{\bowtie}$ email: tra6sdc@leeds.ac.uk
}

Received: 1 March 2021 Revised: 28 May 2021 Accepted: 23 June 2021

Published online: 6 July 2021 
Table 1. The distribution of COVID-19 outcomes by selected UKB factors and the Foresight obesity driven classification.

\begin{tabular}{|c|c|c|c|c|c|c|}
\hline $\begin{array}{l}\text { From } 29 / 01 / \\
2020 \text { to } 30 / 11 / \\
2020\end{array}$ & $\begin{array}{l}\text { Participants } \\
\text { alive on } 29 / 01 / \\
2020\end{array}$ & $\%$ participants tested & $\begin{array}{l}\% \text { participants } \\
\text { tested positive }\end{array}$ & $\begin{array}{l}\% \text { tests } \\
\text { conducted } \\
\text { that are } \\
\text { positive }\end{array}$ & $\begin{array}{l}\% \text { participants } \\
\text { hospitalised U07.X }\end{array}$ & $\begin{array}{l}\text { \% participants } \\
\text { cause of death } \\
\text { (primary and } \\
\text { secondary) } \\
\text { with U07.X }\end{array}$ \\
\hline All & 360,310 & $9.1 \%$ & $1.57 \%$ & $17.2 \%$ & $0.36 \%$ & $0.12 \%$ \\
\hline \multicolumn{7}{|l|}{ Obesity } \\
\hline $\begin{array}{l}\text { Normal/ } \\
\text { under weight }\end{array}$ & 123,201 & $7.9 \%$ & $1.23 \%$ & $15.4 \%$ & $0.20 \%$ & $0.06 \%$ \\
\hline $\begin{array}{l}\text { Living with } \\
\text { obesity }\end{array}$ & 82,424 & $10.8 \%$ & $2.07 \%$ & $19.1 \%$ & $0.60 \%$ & $0.21 \%$ \\
\hline Not Available & 586 & $15.2 \%$ & $1.88 \%$ & $12.4 \%$ & $1.37 \%$ & $0.17 \%$ \\
\hline \multicolumn{7}{|l|}{ Gender } \\
\hline Aged 55 to 59 & 49,503 & $8.3 \%$ & $2.42 \%$ & $29.3 \%$ & $0.21 \%$ & $0.02 \%$ \\
\hline Aged 60 to 64 & 56,026 & $7.8 \%$ & $1.64 \%$ & $21.2 \%$ & $0.19 \%$ & $0.04 \%$ \\
\hline Aged 65 to 69 & 63,927 & $8.1 \%$ & $1.25 \%$ & $15.4 \%$ & $0.30 \%$ & $0.07 \%$ \\
\hline Aged 70 to 74 & 84,640 & $9.3 \%$ & $1.06 \%$ & $11.4 \%$ & $0.37 \%$ & $0.11 \%$ \\
\hline Aged 75 to 82 & 75,069 & $11.8 \%$ & $1.36 \%$ & $11.6 \%$ & $0.68 \%$ & $0.33 \%$ \\
\hline \multicolumn{7}{|l|}{ Ethnicity } \\
\hline White & 342,062 & $9.1 \%$ & $1.54 \%$ & $17.0 \%$ & $0.34 \%$ & $0.11 \%$ \\
\hline Mixed & 2133 & $8.4 \%$ & $1.64 \%$ & $19.4 \%$ & $0.38 \%$ & $0.05 \%$ \\
\hline Asian & 6256 & $11.4 \%$ & $3.07 \%$ & $26.9 \%$ & $0.62 \%$ & $0.14 \%$ \\
\hline Second quintile & 75,403 & $8.8 \%$ & $1.4 \%$ & $16.3 \%$ & $0.3 \%$ & $0.1 \%$ \\
\hline Middle quintile & 75,704 & $8.9 \%$ & $1.5 \%$ & $17.4 \%$ & $0.3 \%$ & $0.1 \%$ \\
\hline Fourth quintile & 75,766 & $9.0 \%$ & $1.6 \%$ & $17.9 \%$ & $0.4 \%$ & $0.1 \%$ \\
\hline $\begin{array}{l}\text { Most deprived } \\
\text { quintile }\end{array}$ & 76,850 & $10.3 \%$ & $2.0 \%$ & $19.5 \%$ & $0.5 \%$ & $0.2 \%$ \\
\hline \multicolumn{7}{|l|}{ Region } \\
\hline North East & 41,491 & $11.3 \%$ & $1.91 \%$ & $16.9 \%$ & $0.32 \%$ & $0.11 \%$ \\
\hline North West & 55,404 & $10.2 \%$ & $2.53 \%$ & $24.7 \%$ & $0.57 \%$ & $0.16 \%$ \\
\hline $\begin{array}{l}\text { Yorkshire and } \\
\text { the Humber }\end{array}$ & 55,939 & $7.3 \%$ & $2.13 \%$ & $29.3 \%$ & $0.40 \%$ & $0.13 \%$ \\
\hline Midlands & 58,548 & $9.7 \%$ & $1.68 \%$ & $17.3 \%$ & $0.42 \%$ & $0.12 \%$ \\
\hline South & 68,648 & $10.6 \%$ & $0.93 \%$ & $8.8 \%$ & $0.21 \%$ & $0.07 \%$ \\
\hline London & 51,970 & $10.0 \%$ & $1.00 \%$ & $10.0 \%$ & $0.36 \%$ & $0.10 \%$ \\
\hline Wales & 14,739 & $2.1 \%$ & $0.94 \%$ & $44.2 \%$ & $0.00 \%$ & $0.11 \%$ \\
\hline Scotland & 13,571 & $0.1 \%$ & $0.02 \%$ & $25.0 \%$ & $0.30 \%$ & $0.18 \%$ \\
\hline
\end{tabular}


Table 1 continued

\begin{tabular}{|c|c|c|c|c|c|c|}
\hline $\begin{array}{l}\text { From } 29 / 01 / \\
2020 \text { to } 30 / 11 / \\
2020\end{array}$ & $\begin{array}{l}\text { Participants } \\
\text { alive on 29/01/ } \\
2020\end{array}$ & $\%$ participants tested & $\begin{array}{l}\% \text { participants } \\
\text { tested positive }\end{array}$ & $\begin{array}{l}\% \text { tests } \\
\text { conducted } \\
\text { that are } \\
\text { positive }\end{array}$ & $\begin{array}{l}\text { \% participants } \\
\text { hospitalised U07.X }\end{array}$ & $\begin{array}{l}\text { \% participants } \\
\text { cause of death } \\
\text { (primary and } \\
\text { secondary) } \\
\text { with U07.X }\end{array}$ \\
\hline \multicolumn{7}{|l|}{ Classification } \\
\hline Active workers & 35,161 & $9.0 \%$ & $2.24 \%$ & $24.9 \%$ & $0.36 \%$ & $0.06 \%$ \\
\hline $\begin{array}{l}\text { Retirees with } \\
\text { healthy lifestyles }\end{array}$ & 77,692 & $9.2 \%$ & $0.92 \%$ & $10.0 \%$ & $0.28 \%$ & $0.10 \%$ \\
\hline $\begin{array}{l}\text { Stressed and } \\
\text { not in work }\end{array}$ & 56,679 & $10.2 \%$ & $1.34 \%$ & $13.2 \%$ & $0.51 \%$ & $0.19 \%$ \\
\hline $\begin{array}{l}\text { Deprived with } \\
\text { less healthy } \\
\text { lifestyles }\end{array}$ & 44,624 & $11.8 \%$ & $1.89 \%$ & $16.1 \%$ & $0.84 \%$ & $0.38 \%$ \\
\hline $\begin{array}{l}\text { Comfortable } \\
\text { professionals }\end{array}$ & 66,195 & $8.0 \%$ & $1.31 \%$ & $16.4 \%$ & $0.22 \%$ & $0.05 \%$ \\
\hline $\begin{array}{l}\text { Comfortable } \\
\text { families }\end{array}$ & 79,959 & $7.9 \%$ & $2.12 \%$ & $27.0 \%$ & $0.16 \%$ & $0.02 \%$ \\
\hline
\end{tabular}

COVID-19) and U07.2 (clinically diagnosed for/probable/suspected COVID-19) are used to identify hospital admissions for COVID-19. Any primary or secondary cause of death mentioning COVID-19 is recorded as a COVID-19 death. All UKB participants with our obesity classifications that were alive on the 29 January 2020, this being the date that COVID-19 cases were first detected in the UK, are included in our 'population at risk'. World Health Organisation cut-points are used to calculate weight status categories from measured height and weight information [17].

Descriptive statistics are calculated for the relationship between our obesity classification and the four COVID-19 outcomes. As well as a consideration of how these events vary by our classification, a confirmatory analysis examines patterns in these data by obesity, gender, age, ethnicity and a measure of area deprivation.

\section{RESULTS}

Descriptive statistics are presented in Table 1 and the standardised differences [18] are provided in Table 2.

In Table 1 a larger proportion of overweight or obese people are tested, test positive and are hospitalised than those who are healthy weight. The proportions that die of/with COVID-19 is highest for those who are living with obesity $(0.21 \%$ versus $0.06 \%$ for normal/underweight and $0.11 \%$ for overweight). The oldest participants (aged 70 to 82 ) have higher testing rates than younger participants $(11.8 \%$ for the oldest group but only $8.4 \%$ for the youngest), however it is younger participants who have higher positive test rates (at $2.67 \%$ ). A higher proportion of older participants are hospitalised (0.68\%) and/or die with/ of COVID-19 (0.33\%) than younger participants (just $0.01 \%)$. Those from Asian and Black ethnic groups have a higher proportion of testing $(11.4 \%$ and $10.1 \%$, respectively) and a higher positive test rate $(3.07 \%$ and $1.79 \%$, respectively) than those from White (1.54\%), Mixed (1.64\%) or Other $(1.47 \%)$ groups. The Black group has the highest percentage of hospitalisation (at $0.81 \%$ ) and/or death $(0.34 \%)$. In terms of deprivation, testing, positive results, hospitalisation and death are all higher for the most deprived quintile $(10.3 \%, 2.0 \%, 0.5 \%$ and $0.2 \%$, respectively) than the least deprived quintile $(8.7 \%$, $1.3 \%, 0.2 \%$ and $0.1 \%$, respectively). In summary, for obesity, gender, age, ethnicity and deprivation, we see trends emerge where most outcomes accord with our understanding that socio-demographic [19] and socio-economic groups [20] have differing outcomes [10,11,21]. This provides reassurance that these data are suitable for further consideration against our obesity classification.
Our classification identifies interesting patterns. The Active workers class are just slightly less likely than average to get tested (at $9.0 \%$ versus $9.1 \%$ ), although those that are tested are more likely than average to test positive (2.24\% versus $1.57 \%)$. Whilst they have a higher percentage of ethnic minority groups, the proportion that are hospitalisation $(0.36 \%)$ or die $(0.06 \%)$ is low, which could be age related in this young class. Testing rates for the Retirees with healthy lifestyle class are just higher than average $(9.2 \%)$ but the rate of positive tests are lower than average $(0.92 \%$ versus $1.57 \%$ ). They are also less likely than average to be hospitalised $(0.28 \%$ versus $0.36 \%)$ or die $(0.10 \%$ versus $0.12 \%)$. Testing rates for the Stressed and not in work class are high (10.2\%) with hospitalisations above average $(0.51 \%$ versus $0.36 \%)$, as is the proportion that die of/with COVID-19 (0.19\% versus $0.12 \%)$. With the Deprived with less-healthy lifestyles class we see the highest testing rates $(11.8 \%)$ and hospitalisation $(0.84 \%)$ and death rates are the highest of any class (0.38\%). Our Comfortable professionals class demonstrate testing rates below average (8.0\% versus $9.1 \%)$, and of those tested, positive test results are also below average (1.31\% versus $1.57 \%)$. This class are also less likely to be hospitalised $(0.22 \%)$ or die of COVID-19 $(0.05 \%)$. Testing rates for the Comfortable families class are the lowest in the cohort (7.9\%), but of those who are tested, positive diagnoses are high (2.12\%), with $27.0 \%$ of tests being positive. Here COVID-19 hospitalisation rates $(0.16 \%)$ and deaths $(0.02 \%)$ are the lowest of all the classes.

In Table 2 there is generally a detectable difference in the distribution of counts for the 'treated' and 'not treated' participantsdemonstrating that there are differences in outcomes due to each of the four treatments. This is, however, not so much the case for gender, where there is no supporting evidence for differences both when testing, and finding a positive test outcome.

\section{DISCUSSION}

Our classification, grounded in a whole systems approach to understanding obesity, differentiates COVID-19 prevalence and severity in a large UK cohort. Of significance is that neither the outcome of obesity itself or COVID-19 outcome were explicitly used in building the classification, yet this differentiating ability is present in the classification. Results show that the Active Workers are the most likely to test positive. This class has a high representation in manual trades who are less likely to be able to work from home during the pandemic and have busy lives, making them less able to adapt. They are, however, healthy enough as a group that a lower proportion are hospitalised with or 
Table 2. Standardised differences for the categorical variables of interest (values above 0.1 are highlighted in bold [23]).

\begin{tabular}{|c|c|c|c|c|}
\hline & $\%$ participants tested & $\begin{array}{l}\% \text { participants tested } \\
\text { positive }\end{array}$ & $\begin{array}{l}\text { \% participants } \\
\text { hospitalised U07.X }\end{array}$ & $\begin{array}{l}\% \text { participants cause of death (primary } \\
\text { and secondary) with U07.X }\end{array}$ \\
\hline Gender & 0.047 & 0.071 & 0.301 & 0.451 \\
\hline Ethnicity & 0.039 & 0.110 & 0.156 & 0.181 \\
\hline Townsend-10 & 0.074 & 0.161 & 0.310 & 0.360 \\
\hline Classification & 0.151 & 0.323 & 0.567 & 0.929 \\
\hline
\end{tabular}

die from/with COVID-19 (this group have a high percentage who self-report no doctor diagnosed illnesses). The Retirees with healthy lifestyle are a class that looks after themselves well and generally have access to the resources which would facilitate the ability to isolate. They have the knowledge and time to be able to get tested, but also demonstrate low positive rates. Being an older demographic who were advised by the government to 'shield', avoids contacts and potential infections, and so they are less likely to test positive, suffer hospitalisation or die. A different picture emerges for Stressed and not in work, where it is possible that these participants present with symptoms or are being tested because they are undergoing other medical treatments (this is one of the two classes that report poor general health and the presence of long standing illnesses-including diabetes and cancer) and would therefore be picked-up through routine testing at hospital admission. Those in this class who do have COVID-19 are more likely to be hospitalised or die.

Another class with poor outcomes is Deprived with lesshealthy lifestyles. These participants may generally lack the necessary societal and economical resources to self-isolate effectively. Additionally, a reason for the high testing rates here could be due to presenting with symptoms or screening as part of other treatments (as was the case for the Stressed and not in work). Their standard of living and older age profile account for high hospitalisation and mortality. The Comfortable professionals class is largely composed of younger, busy individuals and these participants are less likely to get tested. A proportion of these participants have higher qualifications and are employed in professional occupations and many will be working from home, with less exposure. They also live in smaller households, so have a lower likelihood of within household transmission, and in less deprived areas, where rates are lower. Comfortable families are a relatively healthy group who also live in less deprived areas. Given the characteristics of this group any symptoms might not be severe and their testing rates are the lowest of all classes. They did however live in larger households, likely at one time to be containing children or young adults, so the within home transmission may explain the higher positive rates for those who are tested. Lifestyle, age and health may explain hospitalisation and death being low.

As we learn more about risk factors for COVID-19 we begin to understand that they incorporate a complex interplay of a range of biological, social and environmental risks, in a similar manner to obesity. This communication presents a classification tool that is able to highlight at risk groups in the same way that it can distinguish those most likely to be overweight or living with obesity. This may be through obesity acting as mediator for COVID-19 or that the classification captures latent variables that are underlying risk factors for both obesity and COVID-19.

There are known biases in the UKB data which limit the wider generalisability of findings, given that the population is generally white, middle aged and more affluent [22]. That said this work presents an important proof of principle that could be replicated elsewhere. With future data releases, follow up work could investigate whether the classification can be used in understanding long-COVID risk.

\section{REFERENCES}

1. Intensive Care National Audit and Research Centre. COVID-19 report 2020. https://www.icnarc.org/Our-Audit/Audits/Cmp/Reports.

2. Khawaja AP, Warwick AN, Hysi PG, Kastner A, Dick A, Khaw PT, et al. Associations with covid-19 hospitalisation amongst 406,793 adults: the UK Biobank prospective cohort study. medRxiv [Preprit]. 2020.

3. Public Health England. Disparities in the resk and outcomes of COVID-19. 2020.

4. Butland B, Jebb S, Kopelman P, McPherson K, Thomas S, Mardell J, et al. Tackling obesities: future choices-project report. Department of Innovation, Universities and Skills London; 2007.

5. Jarolimova J, Tagoni J, Stern TA. Obesity: its epidemiology, comorbidities, and management. Prim Care Companion CNS Disord. 2013;15:PCC.12f01475.

6. National Health Service. Overview - Obesity. https://www.nhs.uk/conditions/ obesity/ (2020).

7. Loring B, Robertson A. Obesity and inequities. Guidance for addressing inequities in overweight and obesity. World Health Organisation; 2014.

8. Sudlow C, Gallacher J, Allen N, Beral V, Burton P, Danesh J, et al. UK biobank: an open access resource for identifying the causes of a wide range of complex diseases of middle and old age. PLoS Med. 2015;12:e1001779.

9. UK Biobank. UK Biobank makes health data available to tackle COVID-19. https:// www.ukbiobank.ac.uk/2020/04/covid/ (2020).

10. Sattar N, Ho FK, Gill JM, Ghouri N, Gray SR, Celis-Morales CA, et al. BMI and future risk for COVID-19 infection and death across sex, age and ethnicity: preliminary findings from UK biobank. Diabetes Metab Syndr. 2020;14:1149-51.

11. Yates T, Razieh C, Zaccardi F, Davies MJ, Khunti K. Obesity and risk of COVID-19: analysis of UK biobank. Prim Care. Diabetes. 2020;14:566-7.

12. Christensen RAG, Sturrock SL, Arneja J, Brooks JD. Measures of adiposity and risk of testing positive for SARS-CoV-2 in the UK Biobank Study. J Obes. 2021;2021:8837319.

13. Niedzwiedz CL, O'Donnell CA, Jani BD, Demou E, Ho FK, Celis-Morales C, et al. Ethnic and socioeconomic differences in SARS-CoV-2 infection: prospective cohort study using UK Biobank. BMC Medicine. 2020;18:1-14.

14. Hastie CE, Mackay DF, Ho F, Celis-Morales CA, Katikireddi SV, Niedzwiedz CL. et al. Vitamin D concentrations and COVID-19 infection in UK Biobank. Diabetes Metab Syndr. 2020;14:561-65.

15. Clift AK, Coupland CAC, Keogh RH, Diaz-Ordaz K, Williamson E, Harrison EM, et al. Living risk prediction algorithm (QCOVID) for risk of hospital admission and mortality from coronavirus 19 in adults: national derivation and validation cohort study. BMJ. 2020;371:m3731.

16. Clark S, Birkin M, Lomax N, Morris M. Developing a whole systems obesity classification for the UK Biobank Cohort. https://osf.io/7nqgd/download (2020).

17. World Health Organisation. Obesity and overweight. https://www.who.int/newsroom/fact-sheets/detail/obesity-and-overweight (2020).

18. Yang $D$, Dalton JE, editors. A unified approach to measuring the effect size between two groups using SAS ${ }^{\circledR}$. SAS global forum; 2012.

19. Townsend MJ, Kyle TK, Stanford FC. Outcomes of COVID-19: disparities in obesity and by ethnicity/race. Int J Obes. 2020;44:1807-1809. https://doi.org/10.1038/ s41366-020-0635-2. 
20. Mikolai J, Keenan K, Kulu H. Intersecting household-level health and socioeconomic vulnerabilities and the COVID-19 crisis: an analysis from the UK. SSM Popul Health. 2020;12:100628

21. Hamer M, Gale CR, Kivimaki M, Batty GD. Overweight, obesity, and risk of hospitalization for COVID-19: a community-based cohort study of adults in the United Kingdom. Proc Natl Acad Sci USA. 2020;117:21011-3.

22. Fry A, Littlejohns TJ, Sudlow C, Doherty N, Adamska L, Sprosen T, et al. Comparison of sociodemographic and health-related characteristics of UK Biobank participants with those of the general population. Am J Epidemiol. 2017;186: 1026-34

23. Austin PC. Using the standardized difference to compare the prevalence of a binary variable between two groups in observational research. Commun. Stat. Simul. Comput. 2009;38:1228-34.

\section{FUNDING}

This work was supported by the ESRC funded Consumer Data Research Centre for CDRC - Grant reference - ES/S007164/1.

\section{COMPETING INTERESTS}

The authors declare no competing interests.

\section{ADDITIONAL INFORMATION}

Correspondence and requests for materials should be addressed to S.C.

Reprints and permission information is available at http://www.nature.com/ reprints

Publisher's note Springer Nature remains neutral with regard to jurisdictional claims in published maps and institutional affiliations.

(C) Open Access This article is licensed under a Creative Commons Attribution 4.0 International License, which permits use, sharing, adaptation, distribution and reproduction in any medium or format, as long as you give appropriate credit to the original author(s) and the source, provide a link to the Creative Commons license, and indicate if changes were made. The images or other third party material in this article are included in the article's Creative Commons license, unless indicated otherwise in a credit line to the material. If material is not included in the article's Creative Commons license and your intended use is not permitted by statutory regulation or exceeds the permitted use, you will need to obtain permission directly from the copyright holder. To view a copy of this license, visit http://creativecommons. org/licenses/by/4.0/.

(C) The Author(s) 2021 